\title{
Prevalence of Epstein-Barr virus and cytomegalovirus in Bulgarian dental patients
}

\author{
Assya Krasteva $^{1}$, Aneta Ivanova ${ }^{2}$, Angelina Kisselova $^{1}$ \\ 1. Department of Oral and Imaging Diagnostics, \\ Faculty of Dental Medicine, Medical University, \\ Sofia; \\ 2. Clinic of Gastroenterlogy, Sveti Ivan Rilski \\ Hospital, Medical University, Sofia;
}

\begin{abstract}
Background

Epstein-Barr virus and cytomegalovirus are herpesviruses, in which primary infection may be asymptomatic or cause an infectious mononucleosis-like disease. Although the virus typically targets lymphocytes, a particular blood cell involved in the immune response, almost all organ systems can ultimately be affected by EBV infection. Cytomegalovirus is responsible for a significant percentage of asymptomatic viral infections worldwide. It is important that any cell or organ may be infected .

EBV infection is transmitted from person to person by contact with infectious body fluids - saliva, breast milk etc., sexual contact, blood transfusion. CMVC is detected in the saliva of between 11 and $24 \%$ of children attending day-care centers .

Transmition of CMV is by body fluids, sexual contact, blood transfusion, during delivery, or organ transplant .

Aim

The aim of the present study was to assess the prevalence of EBV virus and CMV in consecutive patients who attend a dental office.

\section{Methods}

116 concecutive dental patients participated in the study - 35 male and 81 females, with an average age of $49.3 \pm \mathrm{sd}$ 13.9. years. All the patients underwent oral examination. The clinical findings were common oral pathology, common superficial oral lesions, without any maxillo-facial malignancy. All the participants had no data of any malignancy in any part of the body.
\end{abstract}




\section{Results}

Elevated IgM antibodies to CMV were detedced in $2.8 \%$. $6 \%$ were positive for VCA-IgM antibodies. Positive VCA-IgG was detected in almost $97 \%$ of all tested dental patients and this reveals that the person has a current or recent EBV infection and may have reactivation of EBV.

\section{Conclusion}

This is the first report concerning the prevalence of Epstein-Barr virus and cytomegalovirus in Bulgarian dental patients. The majority of dental patients (95\%) have a chronic infection of EBV and some of them reactivate the virus. $8 \%$ have an acute infection of EBV and 2,8\% of CMV. Coinfections of EBV and CMV were not present in our patients.

Keywords: prevalence, Epstein-Barr virus, cytomegalovirus, dental patients.

\section{Introduction}

Cytomegalovirus is responsible for a significant percentage of asymptomatic viral infections. Virtually any cell or organ may be infected (1). CMV infection occurs frequently worldwide and CMV seroprevalence is estimated to range between $60 \%$ to above $90 \%$ in developed countries, with even higher rates (>90\%) in developing countries $(2,3)$. Bulgarian blood donors were seropositive at a total of $96.7 \%$ and $83.5 \%$ for EBV I CMV respectively (4). During childhood, many people acquire primary infection with cytomegalovirus and if they later become immunosuppressed, CMV is likely to become reactivated $(5, ; 6)$. The effects of human CMV on cellular functions which may be associated with the malignant phenotype include the expression of oncogenes (7).

Melnick and co-workers discuss the association of CMV and a variety of malignancies and conclude that $\mathrm{CMV}$ is an important component of tumorigenesis (8).

In primary infection, EBV infects B cells and can cause mucocutaneous manifestations in infectious mononucleosis or acute EBV-associated syndromes such as Gianotti-Crosti syndrome and hemophagocytic syndrome $(3,9,10)$.

A latent EBV infection may result in diseases and lymphoproliferative disorders such as plasmablastic lymphoma, oral hairyleukoplakia, and post-transplant lymphoproliferative disorders. Latent EBV infection has also been implicated in Burkitt lymphoma, Hodgkin lymphoma, nasopharyngeal carcinoma, and Kikuchi histocytic necrotizing lymphadenitis $(9,11)$.

These two herpesviruses also affects largely the oral structures, resulting in different oral manifestations, lesions and complications in the oral cavity - benign and malignant (2).

\section{Aim}

The aim of the present study was to evaluate the prevalence of Epstein-Barr virus and cytomegalovirus in Bulgarian dental patients. 


\section{Material and Methods}

We decided to inverstigate the presence of Epstein-Barr virus and cytomegalovirus in consecutive dental patients, who sought dental care in the Department of Oral and Imaging Diagnostics, Faculty of Dental Medicine, Medical University, Sofia, from April 2014 to July 2016.

116 patients participated in the study - 35 males and 81 females, with an average age for the group 49.3 \pm sd 13.9 years. All the patients underwent oral examination. The clinical findings were common oral pathology, common superficial oral lesions, without any maxilla-facial malignancy. None of the participants showed data of any malignancy in any part of the body.

Epstein-Barr Virus Antibody to Viral Capsid Antigen IgM ( anti-VCA IgM), Epstein-Barr Virus Antibody to Viral Capsid Antigen IgG (anti-VCA IgG), Epstein-Barr nuclear antigen IgG (anti-EBNA IgG) and CMV IgM were evaluated using the immunochemical technique ELFA (Enzyme-linked Immunofluorescence assay). The results are present in Tabl.1.

\section{Results}

Tabl. 1. Serum levels of CMV and EBV antibodies in consecutive dental patients. Results are expressed by mean and sd

\begin{tabular}{|c|c|c|c|c|c|c|}
\hline Sex & $\mathbf{N}$ & Age & $\begin{array}{c}\text { CMV-IgM } \\
U\end{array}$ & $\begin{array}{c}\text { anti-VCA } \\
\text { IgG } \\
\text { U/mL }\end{array}$ & $\begin{array}{c}\text { anti-VCA } \\
\text { IgM } \\
U / m L\end{array}$ & $\begin{array}{c}\text { anti-EBNA } \\
\text { IgG } \\
\text { U/mL }\end{array}$ \\
\hline Males & 35 & $\begin{array}{c}46.9 \\
\pm 15.04\end{array}$ & $\begin{array}{r}0.313 \\
\pm 0.14\end{array}$ & $\begin{array}{c}342 \pm \\
283\end{array}$ & $\begin{array}{l}11 \pm \\
3.5\end{array}$ & $\begin{array}{c}340 \pm \\
227\end{array}$ \\
\hline Females & 81 & $\begin{array}{c}50 \\
\pm 13.1\end{array}$ & $\begin{array}{c}0.284 \\
\pm 0.142\end{array}$ & $\begin{array}{r}425 \\
\pm 270\end{array}$ & $\begin{array}{c}12.9 \\
\pm 16.9\end{array}$ & $\begin{array}{c}353 \\
\pm 224\end{array}$ \\
\hline Total & 116 & $\begin{array}{r}49.3 \\
\pm 13.9 \\
\end{array}$ & $\begin{array}{c}0.292 \\
\pm 0.143 \\
\end{array}$ & $\begin{array}{r}399 \\
\pm 278 \\
\end{array}$ & $\begin{array}{r}12 \\
\pm 14.3 \\
\end{array}$ & $\begin{array}{r}349 \\
\pm 226 \\
\end{array}$ \\
\hline
\end{tabular}

Tabl. 2. Values above the normal range in patients

\begin{tabular}{|l|c|c|c|c|c|}
\hline \multicolumn{1}{|c|}{ Sex } & $\mathbf{N}$ & $\mathbf{C M V}-\mathbf{I g M}$ & $\begin{array}{c}\text { anti-VCA } \\
\text { IgG U/mL }\end{array}$ & $\begin{array}{c}\text { anti-VCA } \\
\text { IgM U/mL }\end{array}$ & $\begin{array}{c}\text { anti-EBNA } \\
\text { IgG U/mL }\end{array}$ \\
\hline Males & 35 & & & & \\
\hline \% of elevated levels & & 3.2 & 93 & 5.7 & 92 \\
\hline Females & 81 & & & & \\
\hline \% of elevated levels & & 2.6 & 98 & 6.1 & 95 \\
\hline Total \% & & 2.8 & 97 & 6 & 95 \\
\hline
\end{tabular}




\section{CMV-IgM}

We mesured the avarage value of IgM antibody to CMV for all groups of dental patients $0,292 \pm 0.143 \mathrm{U}$ (Tabl. 1). Values above the normal range are $2.8 \%$ (Tabl. 2).

By analyzing the results by gender we established that he elevated values are more pronounced in male patients.

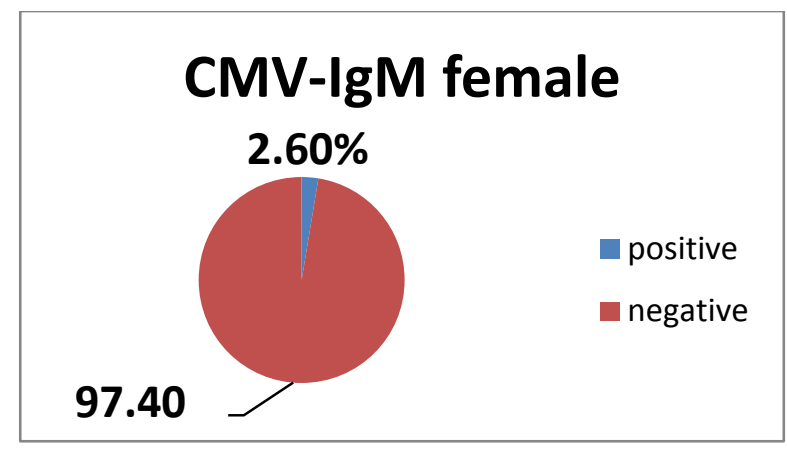

Fig. 1. CMV-IgM serum levels in consecutive female dental patients

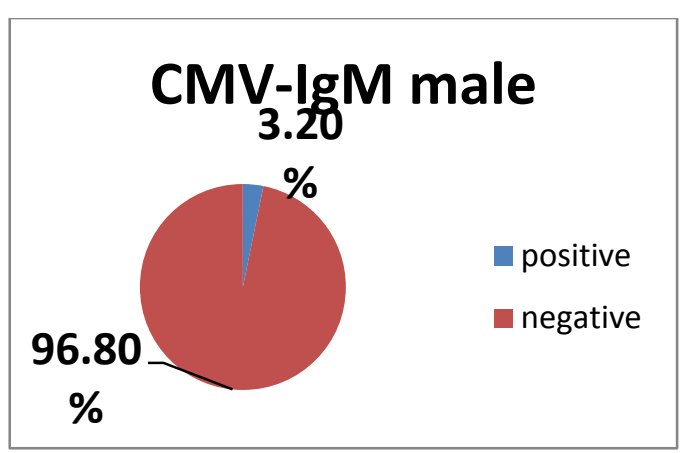

Fig. 2. CMV-IgM serum levels in consecutive male dental patients

In female patients the positive IgM antibody to CMV is 2, 6\% (Fig.1), compared to the positive results in males that amount to 3,20\% (Fig. 2). Acute infection of CMV for all groups is seen in 2,8\% (Fig. 3) without report of general clinical complaints.

Anti-VCA IgM and anti-VCA IgG

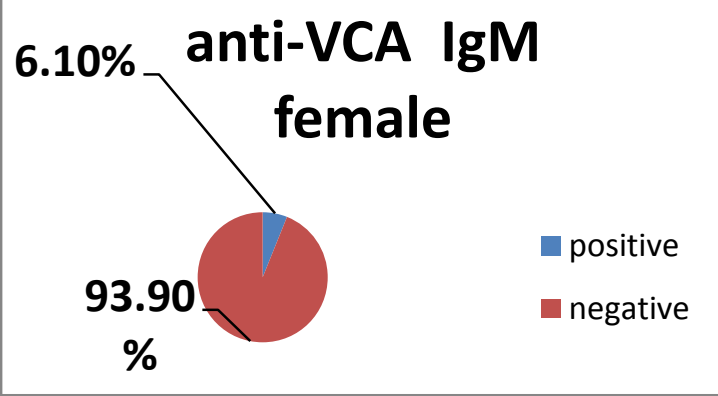

Fig. 3. Anti-VCA IgM serum levels in female consecutive dental patients

\section{anti-VCA IgM male}

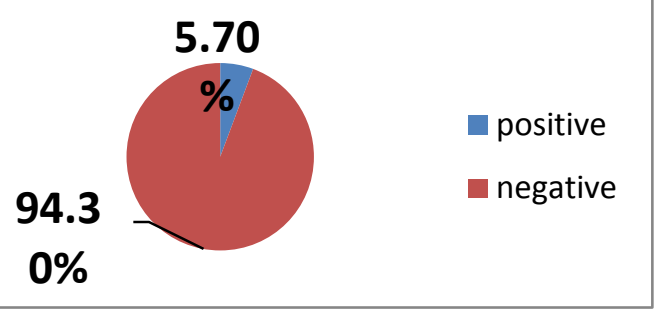

Fig. 4. Anti-VCA IgM serum levels in male consecutive dental patients 
6,10\% females (Fig.3) and 5,7\% (Fig.4) males were detected positive for VCA-IgM antibodies. These results reveal that these patients have an acute infection with EBV. Average value of anti-VCA IgM for the group is $12 \pm 14.3 \mathrm{U} / \mathrm{ml}$ (Tabl. 1$)$.

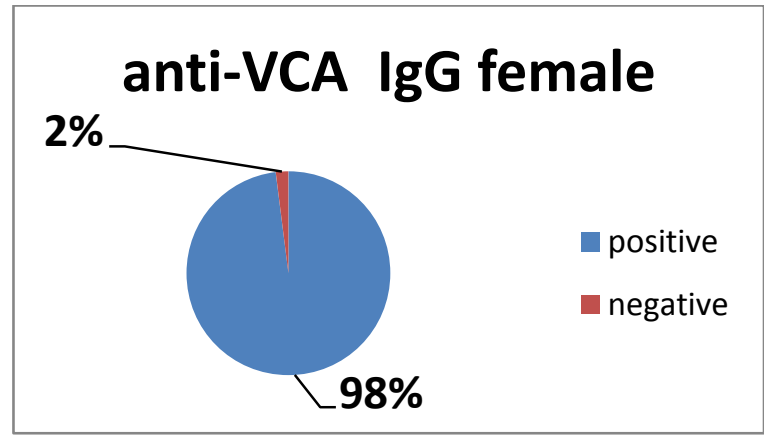

Fig. 5. Anti-VCA IgG serum levels in female consecutive dental patients

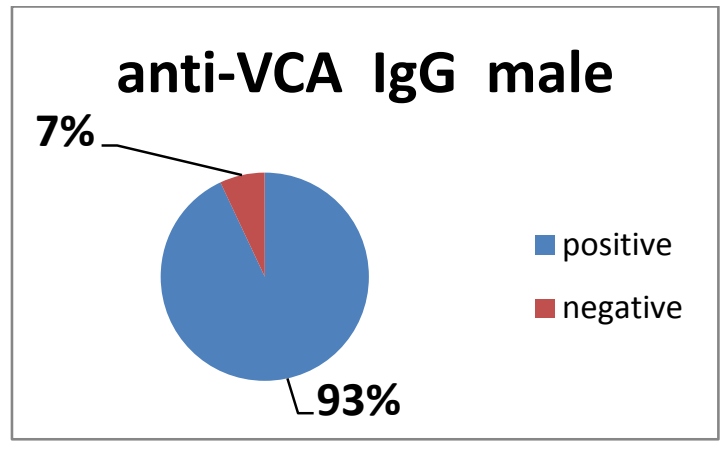

Fig. 6. Anti-VCA IgG serum levels in male consecutive dental patients

Average value of anti-VCA IgG in males is $399 \pm 278 \mathrm{U} / \mathrm{mL}$. It is interesting that in female patients the average value of anti-VCA IgG is higher than in male and the same results we find concerning anti-EBNA IgG (Tabl. 1).

\section{Epstein-Barr nuclear antigen IgG}

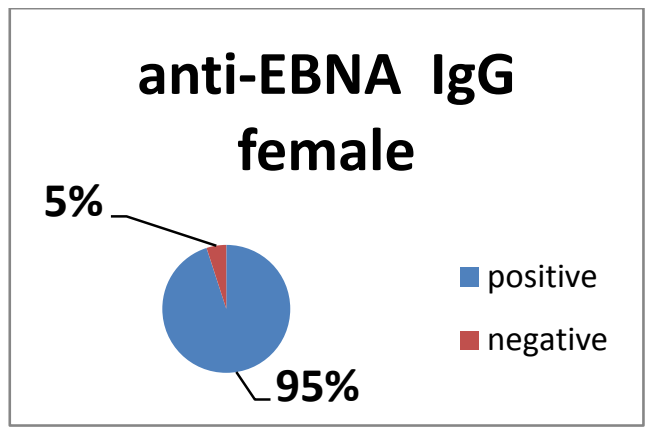

Fig. 7. Anti-EBNA IgG serum levels in consecutive female dental patients

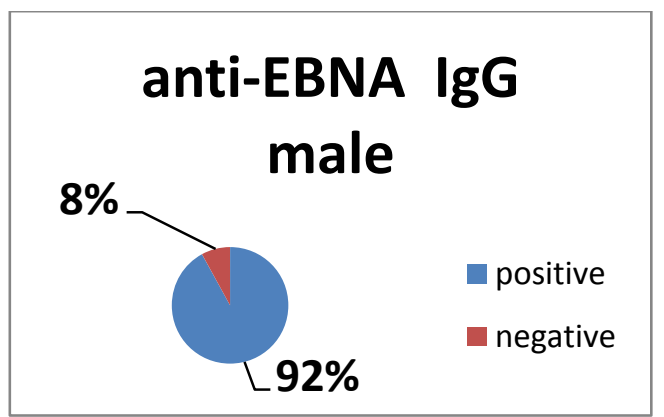

Fig. 8. Anti-EBNA IgG serum levels in consecutive male dental patients

The positive results of IgG EBNA indicated a past infection of EBV or reactivation of the virus. In 92\% of male patients we detected abnormally increased values of anti EBNA IgG (Fig. 8). In female dental patients anti EBNA IgG were elevated in 95\% (Fig. 7).

\section{Discussion}

Serological tests for antibodies specific for Epstein-Barr virus utilize three parameters [viral capsid antigen (VCA) IgG, VCA IgM and EBV nuclear antigen (EBNA)-1 IgG], and it is normally possible to distinguish acute from past infection: the presence of VCA IgM and VCA IgG without EBNA-1 IgG indicates acute 
infection, whereas the presence of VCA IgG and EBNA-1 IgG without VCA IgM is typical of past infection. However, serological findings may sometimes be difficult to interpret as VCA IgG can be present without VCA IgM or EBNA-1 IgG in cases of acute or past infection, or all the three parameters may be detected simultaneously in the case of recent infection or during the course of reactivation (12).

Presence of VCA IgM antibodies indicates recent primary infection with Epstein-Barr virus. In our study VCA IgM antibodies were incresed in $6 \%$ of the patients.

Positive VCA-IgG was detected in almost $97 \%$ of all tested dental patients and this reveals that the person has a current or recent EBV infection and they have inactivation of the virus (Tabl. 2).

Antibodies to EBNA develop 6 to 8 weeks after primary infection and are detectable for life. Over $90 \%$ of the normal adult population has IgG class antibodies to VCA and EBNA. 95\% of our dental patients were with elevated values. The elevated titer of EBNA IgG reveals the degree of reactivation of the virus.

In our patients we detected $97 \%$ and $95 \%$ higher values of anti VCA IgG and anti EBNA IgG respectively, which reflect a chronic infection with the virus. The $2 \%$ of difference between the patients with elevated VCA IgG and negative EBNA IgG is probably due to an acute infection of EBV. In $6 \%$ we detected elevated VCA-IgM. So the acute EBV infection is detected in $8 \%$ of the investigated dental patients.

\section{Co-infection with cytomegalovirus and Epstein-Barr virus}

We detected acute infection to CMC in $2.8 \%$ and to EBV in 6\%. We didn't find coinfection with these two viruses.

In the medical literatute there are reports concerning co-infection with cytomegalovirus and Epstein-Barr virus. D. Olson and co-workers found elevated IgM titres to both CMV and EBV in young women. Both near-simultaneous infections and temporally remote sequential infections with acute CMV triggering an immunoreactivation of EBV are reported in the literature. Recognizing that coinfection with these viruses may modulate the clinical course of disease is important $(13,14)$.

In 208 renal transplantation patients CMV and EBV replications were observed in $22 \%$ and $19 \%$. In our dental patients we found $3 \%$ of acute CMV and 6\% of acute EBV (Tabl. 1). Many of these active virus infections were found to overlap in time (59\% and $74 \%$ of all active CMV and EBV infections, respectively) (15).

\section{EBV and CMV in parodontitis and healthy sites}

Recent investigations suggest that the viruses of the family Herpesviridae are associated with periodontal disease $(16,17,18)$.

Hernández and co-workers detected CMV in $27.3 \%$ of aggressive periodontitis patients, but it was not detected in the chronic form and in healthy subjects (17). Compared to our result we detected that 2,8\% of our patients were with acute CMV. The \% is low and one of the explanations is that our patients were with controlled periodontal health. 
R. Sharma et al. described the prevalence of CMV and EBV-1 in $45 \%$ of cases with aggressive periodontitis. Prevalence of CMV in chronic periodontitis was $20 \%$ and in healthy subjects $10 \%$, while for EBV-1 it was $25 \%$ and $0 \%$, respectively. The virus positive sites showed higher pocket depth compared to virus negative sites (18).

Using saliva as a diagnostic tool, Leon Bilder and co-workers inverstigated CMV in unstimulated saliva and found that chronic periodontitis patients had higher prevalence of CMV and suggested that CMV may play a role in the pathogenesis of chronic periodontitis (16).

Another study reveals that CMV can be found not only at the disease sites, bu also at the healthy sites in periodontitis patients (19). CMV was found in one healthy control while HHV-6 and EBV-1 were not found (19). Hengameh Khosropanah identifies CMV and EBV in saliva. The conclusion of the study was that the highest CMV count was in saliva and tissue samples with PD $>6 \mathrm{~mm}$ (20). In our patients we used serum for the detection of the CMV and EBV.

\section{Conclusion}

This is the first report concerning the prevalence of Epstein-Barr virus and cytomegalovirus in Bulgarian dental patients. The majority of dental patients (95\%) have chronic infection of EBV. $8 \%$ have acute infection of EBV and 2,8\% of CMV. Coinfections with EBV and CMV were not present in our patients.

\section{References}

1. Jones, AC, Freedman, PD, Phelan, JA, et al. Cytomegalovirus infections of the oralcavity. A report of six cases and reviewof the literature. Oral Surg Oral Med Oral Pathol 1993;75:1: 76-85.

2. Krasteva, A. Epstein-Barr virus and cytomegalovirus - two herpes viruses with oral manifestations. J of IMAB 2013; 19: 4:359-362.

3. Greenberger, M, Glick, M, Ship, J. Transplantation Medicine. Burket's Oral Medicine, 11th ed., PMPH-USA, 2008;461-481.

4. Petrova M. Epstein-Barr virus and chronic liver diseases. PhD thesis. Sofia 2008.

5. Patekar, D, Kheur, S, More, P, et al. Prevalence of Viral Coinfections with EBV and CMV and Its Correlation with CD4 Count In HIV-1 Serpositive Patients. J AIDS Clin Res 2015; 6: 520.

6. Dodd, CL, Winkler, JR, Heinic, GS, et al. Cytomegalovirus infection presenting asacute periodontal infection in a patientinfected with the human immuno-deficiency virus. J Clin Periodontol 1993; 20:4: 282-285. 
7. Cinatl, J Jr, Cinatl, J, Vogel, JU, et al. Modulatory effects of humancytomegalovirus infection on malignantproperties of cancer cells. Intervirology 1996; 39:4: 259-269.

8. Melnick, M, Deluca, KA, Sedghizadeh, PP, Jaskoll T. Cytomegalovirus-induced salivary glandpathology: AREG, FGF8, TNF-á, andIL-6 signal dysregulation and neoplasia. Exp Mol Pathol 2013; 94:2: 386-397. DOI: 10.1016/j.yexmp.2013.01.005

9. Mendoza, N, Diamantis, M, Arora, A, et al. Mucocutaneous manifestations of Epstein-Barr virus infection. Am J Clin Dermatol 2008; 9:5: 295-305.

10. Jain, N, Bhatia, V, Lattoo, S. Epstein-Barr virus and associated headand neck manifestations. Ann NigerianMed 2011; 5: 38-41.

11. Song, HM, Wu, XY, Wang, W, et al. Clinical characteristics and follow-up of 12 caseswith severe chronic active Epstein-Barrvirus infection. Zhonghua Er Ke Za Zhi 2009;47:9: 682-686.

12. De Paschale, M, Clerici, P. Serological diagnosis of Epstein-Barr virus infection: Problems and solutions. World J Virol 2012; 1:1: 31-43. doi: 10.5501/wjv.v1.i1.31

13. Olson, D, Huntington, Mark K. Co-infection with cytomegalovirus and Epstein-Barr virus in mononucleosis: case report and review of literature. S D J Med 2009; 62 :9: 349, 351-353.

14. Ito, Y, Shibata-Watanabe, Y, Kawada, J, et al. Cytomegalovirus and Epstein-Barr virus coinfection in three toddlers with prolonged illnesses. J Med Virol. 2009; 81 :8: 1399-1402. doi: 10.1002/jmv.21527.

15. Meyer, T, Scholz, D, Warnecke, G, et al. Importance of simultaneous active cytomegalovirus and Epstein-Barr virus infection in renal transplantation. Clin Diagn Virol. 1996; 6: 79-91.

16. Bilder, L, Elimelech, R, Szwarcwort-Cohen, M, et al. The prevalence of human herpes viruses in the saliva of chronic periodontitis patients compared to oral health providers and healthy controls. Arch Virol 2013;158:1221-1226. DOI: 10.1007/s00705-013-1609-7

17. Hernández, HH, Fernandes, AS, Escalona, et al. Herpes Simplex Virus 1, Cytomegalovirus and Epstein Barr Virus Detection in Patients with Chronic and Aggressive Periodontitis. OALib J 2016; 3:3: 1-9.

18. Sharma, R, Padmalatha, O, Kaarthikeyan, G, et al. Comparative analysis of presence of Cytomegalovirus (CMV) and Epsteinbarr virus -1 (EBV-1) in cases of chronic periodontitis and aggressive periodontitis with controls. Indian J Dent Res 2012; 23:4: 454-458.

19.Tantivanich, S, Laohapand, P, Thaweeboon, S, et al. Prevalence of cytomegalovirus, human herpesvirus-6, and Epstein-Barr virus in periodontitis patients and healthy subjects in the Thai population. - Southeast Asian J Trop Med Public Health 2004; 35:3: 635-640. 
20. Khosropanah, H, Karandish, M, Ziaeyan, M, et al. Quantification of Epstein-Barr Virus and Human Cytomegalovirus in Chronic Periodontal Patients. Jundishapur J Microbiol 2015; 8 :6: e18691.

\section{Corresponding author:}

Associate prof. Assya Krasteva, PhD;

Department of Oral and Imaging Diagnostics,

Faculty of Dental Medicine, Medical University, Sofia

Sofia 1431, 1 "Georgi Sofiiski" Str. 